\title{
CORRESPONDENCE
}

\section{Distinction between good palliative care and intending death}

\author{
E. Wesley Ely ${ }^{*}$ (D, Elie Azoulay and Charlie L. Sprung
}

๑) 2019 Springer-Verlag GmbH Germany, part of Springer Nature

\section{Dear Editor,}

We thank JL Vincent, J Creteur and FS Taccone [1] for their thoughtful comment on our article [2]. There is a key misunderstanding about one term on which the authors did not focus. This is the word "intent."

1. We do not want anyone in critical care to believe that we are speaking against limitation of life support. When a patient or family judges that any intervention (e.g., tracheostomy) is not justifiable or not in the "best interests" of the patient (i.e., its risks and harms clearly outweigh benefit), then it should either be limited or not performed at all.

2. We wrote that we would "never intentionally shorten the life of a patient." When practicing good end-oflife care, we are accompanying patients as they die naturally of their diseases and, when patients or families decide against life-sustaining treatment, we are avoiding the artificial prolongation of their dying process. In accepting the natural dying process and shifting to palliative care, we must always ask ourselves, "Is everything we are providing, such as sedatives and narcotics, intended to comfort and ease suffering?" If the answer is "yes," any potential side effects (such as hypotension or respiratory suppression) that may result in the shortening of life are ethically justifiable because of the rule of double effect, even if they may be foreseeable. The intent of such treatments is to relieve suffering, not end life [3]. If, by contrast, the physician's intention of such treatments is to end or shorten life, physicians cross an ethical line that views (wrongly, we believe) "death-intending

\footnotetext{
*Correspondence: wes.ely@vumc.org
}

Tennessee Valley Veteran's Affairs Geriatric Research Education Clinical Center (VA GRECC), Critical IIIness, Brain Dysfunction, and Survivorship (CIBS) Center, Vanderbilt University Medical Center, Nashville, TN, USA actions" as legitimate forms of medical care. This is a point of professional conviction about which physicians and professional societies disagree. And in response to our colleagues' concerns about competing opinions, we would add that the strength of a moral claim will always depend on the validity of its underlying assumptions and supporting arguments, not merely on the professionals or societies endorsing it. To be clear, we acknowledge that removal of a ventilator or cessation of vasopressors in a patient in ARDS and septic shock (which two of us routinely do -EWE/EA) clearly allows a pathophysiologic process to advance more rapidly toward death, and in that sense the withdrawing of treatment shortens a person's life. But the intent of the removal of the life support is to allow the patient's life to take its natural course without artificial interventions, not to hasten the end of the patient's life. The difference could be viewed as allowing a candle to burn out on its own versus intentionally blowing the candle out.

3. Why is this distinction important? We must uphold the fundamental commitment to "maintain the utmost respect for human life" and preserve the trust essential to the patient-physician relationship [4]. Trust is vulnerable. As reviewed in two recent publications $[5,6]$, there are circumstances when we as Intensivists are in a position to make decisions about patients' treatment in ways that do not involve informed consent. The authors write that increasing doses of opioids and sedatives "should be done only in concert with the relatives." However, all of us care for many unconscious patients who do not have any family present and no one to speak on their behalf. What if we, as the Belgian guidelines controversially recommend, begin habitually and paternalistically "shortening the dying process with use of medication, such as analgesics/sedatives...even in the absence of

\section{6 Springer}


discomfort"? [7, 8]. How many of these patients might have lived after life support is withheld or withdrawn? How often do we get things wrong in our prognostication? Would this patient have preferred another month of life, perhaps to resolve relationships or say goodbyes? Who are we to decide? We may wonder how many of the 1043 patients from Flanders Belgium, reported in NEJM [9] to have received "hastening of death without explicit request of from patient," may have been in such a scenario.

In the end, we must carefully navigate the care of our patients to avoid two extremes at end-of-life: (a) on one hand, we need to avoid useless, burdensome, or unwanted technology when a patient wishes to forgo it or when it is clearly not indicated; (b) on the other hand, once goals of care have shifted to palliation, we need to avoid using medical technology (in this case medications) for the explicit purpose of hastening death, and instead focus only on providing comfort.

\section{Compliance with ethical standards}

\section{Conflicts of interest}

The authors declare that they have no conflicts of interests.

\section{Publisher's Note}

Springer Nature remains neutral with regard to jurisdictional claims in published maps and institutional affiliations.

\section{Author's note}

This is a very heated topic, and the fact that there will be ongoing clarity on these points through this discussion in Intensive Care Medicine is critical to our vocations and to advancing the field in these changing times. We hope that our reply provides the right guidance for ongoing conversations around the world in training programs, ICUs, and in family conferences today and tomorrow.

Accepted: 3 October 2019

Published online: 28 October 2019

\section{References}

1. Vincent JL, Creteur J, Taccone FS (2019) Things we would never do regarding end-of-life care in the ICU. Intensive Care Med. https://doi. org/10.1007/s00134-019-05816-6

2. Ely EW, Azoulay E, Sprung CL (2019) Eight things we would never do regarding end-of-life care in the ICU. Intensive Care Med 45:1116-1118

3. McClelland W, Goligher EC (2019) Withholding or withdrawing life support versus physician-assisted death: a distinction with a difference? Curr Opin Anaesthesiol 32:184-189

4. WMA General Assembly (World Medical Association) Geneva, Switzerland, September 1948. Physician's Pledge, updated at the 68th WMA General Assembly, Chicago US Oct 2017. https://www.wma.net/polic ies-post/wma-declaration-of-geneva/. Accessed Oct 2, 2019

5. Goligher EC, Ely EW, Sulmasy DP, Bakker J, Raphael J, Volandes AE, Patel BM, Payne K, Hosie A, Churchill L, White DB, Downar J (2017) Physicianassisted suicide and euthanasia in the ICU: a dialogue on core ethical issues. Crit Care Med 45:149-155

6. Sprung CL, Somerville MA, Radbruch L, Collet NS, Duttge G, Piva JP, Antonelli M, Sulmasy DP, Lemmens W, Ely EW (2018) Physician-assisted suicide and euthanasia: emerging issues from a global perspective. J Palliat Care 33:197-203

7. Vincent JL, Schetz M, De Waele JJ, de Clety SC, Michaux I, Sottiaux T, Hoste E, Ledoux D, De Weerdt A, Wilmer A, Belgian Society of Intensive Care M (2014) "Piece" of mind: end of life in the intensive care unit statement of the Belgian Society of Intensive Care Medicine. J Crit Care 29:174-175

8. Kompanje EJ, Epker JL, Bakker J (2014) Hastening death due to administration of sedatives and opioids after withdrawal of life-sustaining measures: even in the absence of discomfort? J Crit Care 29:455-456

9. Chambaere K, Vander Stichele R, Mortier F, Cohen J, Deliens L (2015) Recent trends in euthanasia and other end-of-life practices in Belgium. N Engl J Med 372:1179-1181 